\title{
Papers
}

\section{Normal serum aminotransferase concentration and risk of mortality from liver diseases: prospective cohort study}

\author{
Hyeon Chang Kim, Chung Mo Nam, Sun Ha Jee, Kwang Hyub Han, Dae Kyu Oh, Il Suh
}

\begin{abstract}
Objective To examine the relation between the normal range of serum aminotransferase concentration and mortality from liver disease.

Design Prospective cohort study.

Setting Korea Medical Insurance Corporation study with eight years' follow up.

Participants 94533 men and 47522 women aged 35-59 years. Main outcome measure Mortality from liver diseases according to death certificate.

Results There was a positive association between the aminotransferase concentration, even within normal range (35-40 IU/1), and mortality from liver disease. Compared with the concentration $<20 \mathrm{IU} / 1$, the adjusted relative risks for an aspartate aminotransferase concentration of 20-29 IU/1 and $30-39 \mathrm{IU} / 1$ were 2.5 (95\% confidence interval 2.0 to 3.0$)$ and 8.0 (6.6 to 9.8) in men and 3.3 (1.7 to 6.4) and 18.2 (8.1 to 40.4) in women, respectively, The corresponding risks for alanine aminotransferase were 2.9 (2.4 to 3.5$)$ and 9.5 (7.9 to 11.5) in men and 3.8 (1.9 to 7.7$)$ and 6.6 (1.5 to 25.6) in women, respectively. According to receiver operating characteristic curves the best cut-off values for the prediction of liver disease in men were $31 \mathrm{IU} / 1$ for aspartate aminotransferase and 30 IU/l for alanine aminotransferase.

Conclusion People with slightly increased aminotransferase activity, but still within the normal range, should be closely observed and further investigated for liver diseases.
\end{abstract}

\section{Introduction}

Serum aminotransferase assays are the most common laboratory tests for the detection of liver diseases. Because the enzyme concentration in a population forms a continuous distribution, the cut-off concentration that discriminates between healthy and diseased livers is not clearly defined. The upper normal limit of serum aminotransferase is set on average at $40 \mathrm{IU} / \mathrm{l}$, ranging from 30-50 IU/l. ${ }^{2}$ The normal range is calculated from a supposedly healthy reference population. However, reference populations probably include people with mild to moderate chronic liver diseases. ${ }^{3}{ }^{4}$ The use of the current normal range may lead to an underestimated prevalence of liver disease. The normal range may also be determined from prospective studies on the association between enzyme concentration and long term mortality. However, there is little information on the association between serum aminotransferase concentration and mortality from liver diseases, especially for relatively low concentrations of aminotransferase. The significance of serum aminotransferase concentration in relation to mortality needs reviewing, and the need for a full investigation in the general population still remains.

\section{Methods}

\section{Study population}

We selected participants from the cohort used in the Korea Medical Insurance Corporation study. The corporation provides health insurance to government and private school employees and their dependents. In 1990, the corporation insured 1213594 workers and 3389767 dependents, about 11\% of the total Korean population. The corporation required all insured workers to take a biennial health examination. The study cohort consisted of 115200 men and 67932 women, aged 35-59 years in 1990, who underwent health examinations in 1990 and 1992. We had data on serum aminotransferase assay and smoking and alcohol intake for 102741 men and 51180 women. We excluded 162 men and 21 women who died before 1993 and 8046 men and 3637 women who had any known diseases at baseline and enrolled 94533 men and 47522 women for the analysis.

\section{Data collection}

We obtained baseline information from the health examinations in 1990 and 1992 and the self reported questionnaire in 1992. At each examination participants' weight, height, and blood pressure were measured. Fasting blood samples were analysed for plasma glucose concentrations and serum cholesterol and aminotransferase concentrations. The average of two measurements was used for the analysis. From the 1992 questionnaire, we collected information on smoking and alcohol consumption, any previously known diseases, and family history of chronic diseases.

The outcome variable was mortality from death certificates. The follow up period was eight years (1993-2000). We carried out a computerised search of the death certificate data from the National Statistical Office. We used three categories of liver disease classified by ICD-9 or ICD-10 (international classification of diseases, ninth and 10th revisions) for the analysis: liver cancer, liver disease other than cancer, and all liver diseases. In the survival analyses, of the deaths from liver diseases as recorded on the death certificates, we used data only for those patients who had previously been admitted to hospital with liver disease. Information on hospital admissions was obtained from the health insurance claim data.

\section{Statistical analysis}

We classified participants according to body mass index (quarters); serum total cholesterol concentration (quarters); plasma glucose concentration $(<5.6 \mathrm{mmol} / \mathrm{l}, 5.6-6.9 \mathrm{mmol} / \mathrm{l}$, 
Table 1 Baseline characteristics by serum aminotransferase concentration* in 94533 men and 47522 women

\begin{tabular}{|c|c|c|c|c|c|c|c|c|}
\hline \multirow[b]{3}{*}{ Baseline characteristics } & \multicolumn{4}{|c|}{ Men } & \multicolumn{4}{|c|}{ Women } \\
\hline & \multirow{2}{*}{$\begin{array}{c}\text { All levels } \\
(\mathrm{n}=94533)\end{array}$} & \multicolumn{3}{|c|}{ By concentration } & \multirow{2}{*}{$\begin{array}{c}\text { All levels } \\
\text { ( } n=47522)\end{array}$} & \multicolumn{3}{|c|}{ By concentration } \\
\hline & & Normal (n=84 287) & Raised ( $\mathrm{n}=10$ 246) & $P$ value & & Normal (n=46 575) & Raised ( $\mathrm{n}=947)$ & $P$ value \\
\hline \multicolumn{9}{|l|}{ Mean (SD) } \\
\hline Age (years) & $44.8(6.7)$ & $44.8(6.7)$ & $44.4(6.5)$ & $<0.001$ & $42.0(6.0)$ & $42.0(6.0)$ & $44.5(6.8)$ & $<0.001$ \\
\hline Body mass index, $\mathrm{kg} / \mathrm{m}^{2}$ & $23.4(2.4)$ & $23.3(2.3)$ & $23.4(2.6)$ & $<0.001$ & $22.2(2.4)$ & $22.2(2.4)$ & $23.7(3.0)$ & $<0.001$ \\
\hline Systolic blood pressure $(\mathrm{mm} \mathrm{Hg})$ & $125.2(13.9)$ & $124.8(13.7)$ & $128.8(14.6)$ & $<0.001$ & $115.8(12.2)$ & $115.7(12.1)$ & $120.9(14.9)$ & $<0.001$ \\
\hline Diastolic blood pressure (mm Hg) & $82.0(9.4)$ & $81.7(9.4)$ & $84.3(9.7)$ & $<0.001$ & $75.3(8.8)$ & $75.2(8.8)$ & $78.8(10.2)$ & $<0.001$ \\
\hline Fasting plasma glucose (mmol/l) & $5.1(1.0)$ & $5.1(1.0)$ & $5.4(1.2)$ & $<0.001$ & $4.8(0.6)$ & $4.8(0.6)$ & $5.1(1.0)$ & $<0.001$ \\
\hline Total serum cholesterol (mmol/) & $5.0(0.9)$ & $5.0(0.8)$ & $5.2(1.0)$ & $<0.001$ & $4.9(0.8)$ & $4.9(0.8)$ & $5.2(1.0)$ & $<0.001$ \\
\hline Serum AST (IU/I) & $25.7(13.3)$ & $23.0(5.7)$ & $48.0(28.3)$ & $<0.001$ & $20.3(7.2)$ & $19.8(5.0)$ & $46.4(26.2)$ & $<0.001$ \\
\hline Serum ALT (IU/I) & $25.2(15.9)$ & $21.5(6.7)$ & $55.5(30.9)$ & $<0.001$ & $17.4(8.9)$ & $16.7(5.5)$ & $54.1(33.1)$ & $<0.001$ \\
\hline \multicolumn{9}{|l|}{ Number (\%) } \\
\hline \multicolumn{9}{|l|}{ Smoking status: } \\
\hline Non-smoker & $20147(21.3)$ & $18160(21.5)$ & 1987 (19.4) & $<0.001$ & $47131(99.2)$ & $46193(99.2)$ & 938 (99.1) & 0.797 \\
\hline Ex-smoker & $19477(20.6)$ & $17498(20.8)$ & $1979(19.3)$ & & $391(0.8) \dagger$ & $382(0.8) \dagger$ & $9(0.9) \dagger$ & \\
\hline Current smoker & $54909(58.1)$ & $48629(57.7)$ & $6280(61.3)$ & & & & & \\
\hline \multicolumn{9}{|l|}{ Average alcohol consumption: } \\
\hline Non-drinker & $27643(29.2)$ & 24961 (29.6) & $2682(26.2)$ & $<0.001$ & 44933 (94.5) & 44046 (94.5) & $887(93.7)$ & 0.253 \\
\hline$<50$ g/day & $57901(61.3)$ & $51832(61.5)$ & 6069 (59.2) & & $2559(5.5) \ddagger$ & $2529(5.5) \ddagger$ & $60(6.3) \ddagger$ & \\
\hline$\geq 50 \mathrm{~g} / \mathrm{day}$ & $8989(9.5)$ & 7494 (8.9) & $1495(14.6)$ & & & & & \\
\hline \multicolumn{9}{|l|}{ Family history of liver disease: } \\
\hline Yes & $3436(3.6)$ & $2994(3.6)$ & $442(4.3)$ & $<0.001$ & $482(1.0)$ & $464(1.0)$ & $18(1.9)$ & 0.010 \\
\hline No/unknown & $91097(96.4)$ & $81293(96.4)$ & 9804 (95.7) & & $47040(99.0)$ & $46111(99.0)$ & $929(98.1)$ & \\
\hline
\end{tabular}

AST=aspartate aminotransferase, ALT=alanine aminotransferase.

${ }^{*}$ Aminotransferase concentration defined as normal when AST $<40 \mathrm{IU} / \mathrm{I}$ and $\mathrm{ALT}<40 \mathrm{IU} / \mathrm{I}$ and raised when AST $\geq 40 \mathrm{IU} / \mathrm{I}$ and/or ALT $\geq 40 \mathrm{IU} / \mathrm{l}$.

†Smoking in women defined as non-smoker or any smoking.

$\ddagger$ Alcohol consumption in women defined as non-drinker or any drinking.

and $\geq 7.0 \mathrm{mmol} / \mathrm{l}$ ); blood pressure (normal, prehypertension, hypertension ${ }^{5}$ ); smoking (current smokers, former smokers, nonsmokers); and alcohol consumption (non-drinker and four groups of drinkers based on the average daily alcohol intake: $<50 \mathrm{~g} /$ day, $50-99 \mathrm{~g} /$ day, $100-199 \mathrm{~g} /$ day, and $\geq 200 \mathrm{~g} /$ day). We calculated daily intake of alcohol by multiplying the frequency and the amount of alcohol consumed a day for those who drank once a week or more on average. The family history of liver disease was used as a dichotomous variable: no/unknown and yes. Cox proportional hazard regression analysis was used to control for age and the above variables. We have represented multivariate adjusted relative risks of mortality with $95 \%$ confidence intervals, which were estimated by treating the relative risks as floating absolute risks to show the appropriate variability for each concentration of serum aminotransferase. ${ }^{6}$

We plotted the receiver operating characteristic curve of the serum aminotransferase concentration for the detection of future mortality from liver disease. Usually the best cut-off value in a receiver operating characteristic curve is the value that maximises the sum of the sensitivity and specificity, which is the point nearest to the top left hand corner.

\section{Results}

At the baseline examination, aminotransferase concentration was positively associated with blood pressure, fasting plasma glucose concentration, and total serum cholesterol concentration. Cigarette smoking, alcohol consumption, and the family history of liver disease were also associated with raised aminotransferase concentrations (table 1).

During the eight years' follow up 3392 men and 394 women died. The mortality per 100000 person years was 456 for men and 104 for women. The number of deaths from liver disease was 690 , and 524 were confirmed by the previous admission history. Mortality from liver disease was positively associated with baseline age, serum aminotransferase concentration, and blood pressure in both sexes. Family history of liver diseases, high fasting plasma glucose concentration, low total serum cholesterol concentration, and heavy drinking were also correlated with mortality from liver disease in men (table 2).

There was a continuous and positive association between aminotransferase concentration and mortality in men. Mortality from diseases of the digestive system, in which liver diseases accounted for $89 \%$, was most strongly correlated to the aminotransferase concentration. Mortality from cancer and cardiovascular disease was also correlated with aminotransferase concentration. Because of the relatively small number of deaths from liver diseases in women, we could not adequately assess the cause specific mortality (table 3 ).

The association between the aminotransferase concentration and mortality from liver disease was significant, even within the current normal limits. Compared with the lowest concentration $(<20 \mathrm{IU} / \mathrm{l})$, the risks for mortality from liver disease for aspartate and alanine aminotransferase concentrations at 20-29 IU/l (only in men) and 30-39 IU/1 were significantly increased. Both liver cancer and liver disease other than cancer were associated with the serum aminotransferase concentration in men (table 4), but liver disease in women could not be classified (table 5).

We estimated that the best cut-off values for identifying men who are risk of death from liver disease were 31 IU/l for aspartate aminotransferase and $30 \mathrm{IU} / 1$ for alanine aminotransferase. The areas under the receiver operating characteristic curve were 0.83 and 0.78 , respectively (fig 1 ). We could not establish the cutoff value in women, but we would expect it to be lower than in men.

\section{Discussion}

The cross sectional association between serum aminotransferase concentration and liver disease is well known. However, little is 
Table 2 Association between baseline characteristics and risk of mortality from liver diseases. Figures are relative risks ( $95 \%$ confidence intervals)

\begin{tabular}{|c|c|c|}
\hline Baseline characteristics & Men & Women \\
\hline Age (per one year increase) & 1.05 (1.04 to 1.06$)$ & $1.14(1.07$ to 1.21$)$ \\
\hline Raised AST ( $\geq 40 \mathrm{IU} / \mathrm{I})$ & 18.17 (15.24 to 21.66) & 22.53 (8.36 to 60.67) \\
\hline Raised ALT ( $\geq 40 \mathrm{IU} / \mathrm{l})$ & 8.93 (7.49 to 10.64) & 27.32 (11.24 to 66.40$)$ \\
\hline Family history of liver disease & 2.62 (1.93 to 3.56$)$ & - \\
\hline \multicolumn{3}{|l|}{ Body mass index ${ }^{*}\left(\mathrm{~kg} / \mathrm{m}^{2}\right)$ : } \\
\hline$<21.75(<20.51)$ & 1.00 & 1.00 \\
\hline $21.75-23.38$ (20.51-22.06) & 0.87 (0.68 to 1.10$)$ & 0.76 (0.17 to 3.37$)$ \\
\hline $23.39-25.0(22.07-23.72)$ & 0.82 (0.64 to 1.05$)$ & 0.25 (0.03 to 2.27$)$ \\
\hline$\geq 25.01(\geq 23.75)$ & 0.83 (0.65 to 1.06$)$ & 3.83 (1.27 to 11.55$)$ \\
\hline \multicolumn{3}{|l|}{ Blood pressure: } \\
\hline Normal & 1.00 & 1.00 \\
\hline Prehypertension & $1.11(0.89$ to 1.39$)$ & 2.99 (1.21 to 7.41$)$ \\
\hline Hypertension & 1.91 (1.46 to 2.49$)$ & $3.63(0.75$ to 17.45$)$ \\
\hline \multicolumn{3}{|l|}{ Fasting plasma glucose $(\mathrm{mmol} / \mathrm{l})$ : } \\
\hline$<6.1$ & 1.00 & 1.00 \\
\hline $6.1-6.9$ & 2.10 (1.77 to 2.57 ) & 0.68 (0.09 to 5.04) \\
\hline$\geq 7.0$ & 3.18 (2.29 to 4.42$)$ & - \\
\hline \multicolumn{3}{|l|}{ Total serum cholesterol ${ }^{*}(\mathrm{mmol} / \mathrm{l})$ : } \\
\hline$<4.4(<4.3)$ & 1.00 & 1.00 \\
\hline $4.4-4.8(4.3-4.7)$ & 0.63 (0.50 to 0.79$)$ & 1.32 (0.46 to 3.80$)$ \\
\hline $4.9-5.4(4.8-5.3)$ & 0.49 (0.38 to 0.62$)$ & 0.97 (0.31 to 3.01$)$ \\
\hline$\geq 5.5(\geq 5.4)$ & 0.48 (0.37 to 0.61$)$ & 0.50 (0.13 to 2.01$)$ \\
\hline \multicolumn{3}{|l|}{ Smoking: } \\
\hline Non-smoker & 1.00 & 1.00 \\
\hline Past smoker & 1.07 (0.81 to 1.42$)$ & - \\
\hline Current smoker & 1.20 (0.95 to 1.51$)$ & - \\
\hline Ever smoked & - & 5.53 (0.75 to 41.04$)$ \\
\hline \multicolumn{3}{|l|}{ Alcohol consumption (g/day): } \\
\hline Non-drinker & 1.00 & 1.00 \\
\hline$<50$ & 0.78 (0.64 to 0.94$)$ & - \\
\hline $50-99$ & 0.96 (0.68 to 1.35 ) & - \\
\hline 100-199 & 1.09 (0.58 to 2.06$)$ & - \\
\hline$\geq 200$ & 3.33 (1.64 to 6.76$)$ & - \\
\hline Drinker & - & 1.66 (0.39 to 7.08$)$ \\
\hline
\end{tabular}

AST=aspartate aminotransferase, ALT=alanine aminotransferase

${ }^{*}$ Figures in parentheses are ranges for women.

known about the enzyme concentrations in relation to prospective mortality. We found a strong relation between aminotransferase concentrations and long term mortality. We also found that a slightly increased but still normal aminotransferase concentration is related to increased risk of death from liver disease.

\section{Mortality from liver disease and normal serum aminotransferase concentration}

There could be several explanations for the increased risk of mortality in men with slightly increased but still normal enzyme concentrations. Firstly, mortality may be due to unrecognised liver diseases. Several studies have reported the presence of liver diseases in men (chronic active or persistent hepatitis and cirrhosis) with the normal or slightly increased aminotransferase concentration. ${ }^{7-9}$ Chronic hepatitis $\mathrm{C}$ virus infection in people with a persistently normal aminotransferase concentration (HCV with PNAL) also has been reported. ${ }^{10-13}$ Secondly, the relation may be due to other risk factors for liver disease. Aminotransferase activity is associated with factors such as obesity, alcohol consumption, serum cholesterol concentration, and plasma glucose concentration. ${ }^{14-16}$ Even after we adjusted for such risk factors, we observed an independent association between the aminotransferase concentration and mortality from liver disease. Thirdly, advanced chronic liver diseases with relatively low enzyme activity may contribute to the association.
This is unlikely, however, as we excluded men with known liver diseases and used the average of two enzyme measurements at two year intervals. Our data suggest that the association is probably due to unrecognised liver diseases. Individuals with slightly increased aminotransferase concentrations need close observation and further investigation for liver diseases.

Though we consistently observed an association between serum aminotransferase concentration and mortality from liver disease in men, we could not do so in women because mortality from liver diseases in woman is low. In Korea the prevalance of hepatitis B infection in men is twice as high as in women. We speculated that men with hepatitis $\mathrm{B}$ virus infection are at higher risk of liver deterioration. In fact, mortality from liver disease in Korean men is four times higher than in women. ${ }^{17} 18$ Further studies are required to determine the normal range and the impact of serum aminotransferase concentration in women.

\section{Application of results}

Recently, Prati et al proposed that the upper normal limit of serum alanine aminotransferase should be revised to $30 \mathrm{IU} / \mathrm{l}^{4}$ The outcome of the application of the updated normal upper limit is increased sensitivity $(76.3 \%)$ with acceptable specificity $(88.5 \%)$ in identifying active $\mathrm{C}$ viral hepatitis during six month follow up. ${ }^{4}$ Our data agree with this report. If we applied the new cut-off value, the sensitivity of the tests in identifying men who at risk of death from liver disease would be increased from $52.3 \%$ to $69.7 \%$ for aspartate aminotransferase and from $44.5 \%$ to $65.4 \%$ for alanine aminotransferase.

However, updating the current normal range remains controversial. Lowering the upper normal limits will increase the number of asymptomatic patients with abnormal aminotransferase concentration, which may increase the healthcare costs. The lower upper limit will limit blood supplies. ${ }^{19}$ While sensitivity and specificity are constant properties of a test, predictive value is highly dependent on the prevalence of disease in the population. Although the aminotransferase tests have reasonable sensitivity and specificity, their positive predictive value is low: $3.66 \%$ with the current normal range and $1.93 \%$ with the normal range proposed in this study. Because we used mortality as the end point, the values may be much lower than the real value. The low predictive value may be still a problem, especially in a population with a relatively low prevalence of liver disease. A more practical solution may be to divide the current normal upper limit into the optimal concentration $(<30 \mathrm{IU} / \mathrm{l})$ and the borderline concentration (30-39 IU/l). Individuals with a borderline aminotransferase concentration may be candidates for further studies ${ }^{4}$ on secondary prevention of liver diseases.

Although the specificity is low, the serum aminotransferase assay is an inexpensive and useful test in screening for liver disease, especially in areas where liver diseases are prevalent. Lowering the upper limit in such areas will facilitate early detection of chronic liver diseases and thus possibly prevent mortality. In most Western regions, the aminotransferase assay may be less useful as a mass screening tool, though reviewing the normal range of serum aminotransferase concentration may still be useful in special settings such as screening of blood donors, medical check up of haemodialysis patients, and preoperative evaluation. People who repeatedly show increased aminotransferase concentrations according to the lowered normal upper limit should be further investigated by serum biochemistry, viral marker tests, and ultrasonography. The cost effectiveness of this 
Table 3 Relative risk of mortality by all causes by the serum aminotransferase concentration at baseline (expressed as floating absolute risks)

\begin{tabular}{|c|c|c|c|c|c|c|c|c|c|}
\hline & \multirow[b]{2}{*}{$\begin{array}{l}\text { Total No of } \\
\text { Participants }\end{array}$} & \multicolumn{2}{|c|}{ All causes } & \multicolumn{2}{|c|}{ Cancers } & \multicolumn{2}{|c|}{ Cardiovascular diseases } & \multicolumn{2}{|c|}{ Diseases of digestive system } \\
\hline & & $\begin{array}{c}\text { No of } \\
\text { deaths }\end{array}$ & $\mathrm{RR}^{\star}(95 \% \mathrm{Cl})$ & $\begin{array}{c}\text { No of } \\
\text { deaths }\end{array}$ & $\mathrm{RR}^{\star}(95 \% \mathrm{Cl})$ & $\begin{array}{l}\text { No of } \\
\text { deaths }\end{array}$ & $\mathrm{RR}^{*}(95 \% \mathrm{Cl})$ & $\begin{array}{l}\text { No of } \\
\text { deaths }\end{array}$ & $\mathrm{RR}^{\star}(95 \% \mathrm{Cl})$ \\
\hline \multicolumn{10}{|l|}{ Men } \\
\hline \multicolumn{10}{|c|}{ AST (IU/I): } \\
\hline$<20$ & 26416 & 619 & $1.0(0.9$ to 1.1$)$ & 292 & 1.0 (0.9 to 1.1$)$ & 118 & 1.0 (0.8 to 1.2) & 18 & 1.0 (0.6 to 1.6$)$ \\
\hline $20-29$ & 48185 & 1494 & $1.3(1.2$ to 1.4$)$ & 665 & 1.2 (1.1 to 1.3$)$ & 318 & $1.4(1.2$ to 1.5$)$ & 58 & 1.8 (1.4 to 2.4$)$ \\
\hline $30-39$ & 13964 & 590 & 1.7 (1.6 to 1.9$)$ & 262 & 1.7 (1.5 to 1.9$)$ & 107 & 1.4 (1.2 to 1.7$)$ & 51 & 5.6 (4.2 to 7.3 ) \\
\hline $40-49$ & 3127 & 219 & 2.7 (2.4 to 3.1$)$ & 98 & 2.8 (2.3 to 3.4$)$ & 33 & 1.8 (1.3 to 2.5$)$ & 36 & 16.9 (12.2 to 23.5) \\
\hline $50-99$ & 2397 & 358 & 5.4 (4.9 to 6.0$)$ & 158 & 5.5 (4.7 to 6.4$)$ & 39 & 2.6 (1.9 to 3.6$)$ & 79 & 42.7 (34.1 to 53.6) \\
\hline$\geq 100$ & 444 & 112 & 8.6 (7.2 to 10.4) & 39 & 6.7 (4.9 to 9.2 ) & 9 & 3.3 (1.7 to 6.4$)$ & 46 & 120.4 (89.2 to 162.5$)$ \\
\hline \multicolumn{10}{|l|}{ ALT (IU/I): } \\
\hline$<20$ & 37425 & 1061 & 1.0 (0.9 to 1.1) & 494 & 1.0 (0.9 to 1.1$)$ & 197 & 1.0 (0.9 to 1.2) & 34 & 1.0 (0.7 to 1.4$)$ \\
\hline $20-39$ & 36589 & 1197 & 1.2 (1.1 to 1.3$)$ & 535 & 1.2 (1.1 to 1.3$)$ & 263 & 1.3 (1.2 to 1.5$)$ & 61 & 2.1 (1.6 to 2.7) \\
\hline $30-39$ & 11975 & 516 & 1.7 (1.5 to 1.8$)$ & 215 & 1.6 (1.4 to 1.8$)$ & 85 & 1.3 (1.0 to 1.6$)$ & 60 & 6.9 (5.4 to 9.0$)$ \\
\hline $40-49$ & 4068 & 225 & 2.2 (1.9 to 2.5) & 93 & 2.1 (1.7 to 2.6$)$ & 38 & 1.7 (1.2 to 2.3 ) & 40 & 13.5 (9.9 to 18.5$)$ \\
\hline $50-99$ & 3887 & 310 & 3.0 (2.7 to 3.4$)$ & 133 & 3.1 (2.6 to 3.6$)$ & 32 & 1.4 (1.0 to 2.0$)$ & 72 & 23.4 (18.5 to 29.6 ) \\
\hline$\geq 100$ & 589 & 83 & 5.2 (4.2 to 6.4$)$ & 44 & 6.2 (4.6 to 8.3) & 9 & 2.9 (1.5 to 5.6$)$ & 21 & 41.0 (26.7 to 63.1) \\
\hline \multicolumn{10}{|l|}{ Women } \\
\hline \multicolumn{10}{|l|}{ AST (IU/I): } \\
\hline$<20$ & 25362 & 185 & 1.0 (0.9 to 1.2) & 104 & 1.0 (0.8 to 1.2$)$ & 28 & $1.0(0.7$ to 1.6$)$ & 1 & 1.0 (0.1 to 7.1$)$ \\
\hline $20-29$ & 19463 & 174 & 1.0 (0.9 to 1.2) & 113 & 1.2 (1.0 to 1.5$)$ & 22 & 0.7 (0.5 to 1.1) & 2 & 2.3 (0.3 to 16.7) \\
\hline $30-39$ & 2114 & 24 & $1.2(0.7$ to 1.6$)$ & 12 & 1.0 (0.6 to 1.8$)$ & 2 & 0.4 (0.1 to 1.6$)$ & 2 & 18.5 (2.8 to 139.6$)$ \\
\hline $40-49$ & 336 & 3 & $0.8 \quad(0.3$ to 2.5$)$ & 3 & 1.5 (0.5 to 4.6$)$ & 0 & - & 0 & - \\
\hline$\geq 50$ & 247 & 8 & 2.9 (1.4 to 5.8$)$ & 3 & 2.1 (0.7 to 6.5$)$ & 0 & - & 3 & - \\
\hline \multicolumn{10}{|c|}{ ALT (IU/I): } \\
\hline$<20$ & 35187 & 257 & 1.0 (0.9 to 1.2$)$ & 154 & 1.0 (0.8 to 1.2$)$ & 32 & 1.0 (0.6 to 1.6$)$ & 2 & $1.0(0.3$ to 4.0$)$ \\
\hline $20-29$ & 10201 & 103 & 1.2 (1.0 to 1.4$)$ & 62 & 1.2 (0.9 to 1.5$)$ & 17 & 1.3 (0.8 to 2.2$)$ & 2 & 2.7 (0.7 to 11.8$)$ \\
\hline $30-39$ & 1380 & 19 & 1.4 (0.9 to 2.2) & 11 & $1.4(0.8$ to 2.6$)$ & 3 & $1.3(0.4$ to 4.1$)$ & 0 & - \\
\hline $40-49$ & 365 & 10 & 3.0 (1.6 to 5.6) & 6 & 3.1 (1.4 to 6.8$)$ & 0 & - & 2 & 75.0 (19.7 to 314.7) \\
\hline$\geq 50$ & 389 & 5 & 1.2 (0.5 to 3.0$)$ & 2 & 0.9 (0.2 to 3.5$)$ & 0 & - & 2 & 80.8 (19.7 to 314.4) \\
\hline
\end{tabular}

AST=aspartate aminotransferase, ALT=alanine aminotransferase.

*Adjusted for age, body mass index, smoking status, alcohol consumption, plasma glucose, serum total cholesterol, blood pressure, and family history of liver disease.

approach still needs to be evaluated prospectively in various settings.

\section{Strength and weakness}

This study has several strong points. Firstly, it was performed with a large population (142 055 people) and had a long follow up period (eight years). Previous studies have had a cross sectional design or short follow up period, and they failed to investigate the association between serum aminotransferase concentration and long term mortality. ${ }^{40-22}$ Eight years may not be long enough to follow the entire clinical course of liver disease because of its wide variation. However, we had a considerable number of outcome events because of the large study population and the high prevalence of liver diseases in Korea. Secondly, the results can be generalised to the broader Korean population and, perhaps, to other populations as well. While previous studies investigated special populations, such as blood donors and haemodialysis patients, our study cohort was recruited from the nationwide general population. ${ }^{40-22}$ Thirdly, the use of repeated measurements of variables decreased the possibility of measurement error or misclassification bias. Finally, to increase the validity of the causes of death, we verified

Table 4 Relative risk of mortality from liver diseases in men by serum aminotransferase concentration at baseline (expressed as floating absolute risks)

\begin{tabular}{|c|c|c|c|c|c|c|c|}
\hline & \multirow{2}{*}{$\begin{array}{l}\text { Total No of } \\
\text { participants }\end{array}$} & \multicolumn{2}{|c|}{ Liver diseases } & \multicolumn{2}{|c|}{ Liver cancer } & \multicolumn{2}{|c|}{ Non-cancer liver diseases } \\
\hline & & No of deaths & $\mathrm{RR}^{*}(95 \% \mathrm{Cl})$ & No of deaths & $\mathrm{RR}^{*}(95 \% \mathrm{CI})$ & No of deaths & $\mathrm{RR}^{*}(95 \% \mathrm{Cl})$ \\
\hline \multicolumn{8}{|c|}{ AST (IU/I): } \\
\hline$<20$ & 26416 & 25 & $1.0 \quad(0.7$ to 1.5$)$ & 14 & 1.0 (0.6 to 1.7$)$ & 11 & $\begin{array}{ll}1.0 & \text { (0.6 to } 1.8)\end{array}$ \\
\hline $20-29$ & 48185 & 108 & 2.5 (2.0 to 3.0$)$ & 76 & $3.1 \quad(2.5$ to 3.9$)$ & 32 & $1.7 \quad$ (1.2 to 2.3$)$ \\
\hline $30-39$ & 13964 & 98 & 8.0 (6.6 to 9.8) & 64 & 9.4 (7.4 to 12.0$)$ & 34 & $6.2 \quad$ (4.4 to 8.7$)$ \\
\hline $40-49$ & 3127 & 70 & 25.7 (20.3 to 32.5$)$ & 44 & 29.5 (21.9 to 39.8$)$ & 26 & 20.8 (14.1 to 30.6$)$ \\
\hline $50-99$ & 2397 & 149 & 65.7 (55.8 to 77.4$)$ & 92 & 74.6 (60.7 to 91.8$)$ & 57 & $55.0 \quad$ (42.2 to 71.7$)$ \\
\hline$\geq 100$ & 444 & 51 & 111.3 (84.0 to 147.4) & 17 & 65.4 (30.4 to 105.9) & 34 & 167.2 (117.8 to 237.2) \\
\hline \multicolumn{8}{|c|}{ ALT (IU/I): } \\
\hline$<20$ & 37425 & 45 & $1.0 \quad(0.7$ to 1.4$)$ & 27 & $1.0 \quad(0.7$ to 1.5$)$ & 18 & $1.0 \quad$ (0.6 to 1.6$)$ \\
\hline $20-29$ & 36589 & 113 & 2.9 (2.4 to 3.5$)$ & 82 & 3.4 (2.8 to 4.3$)$ & 31 & $2.0 \quad$ (1.4 to 2.8$)$ \\
\hline $30-39$ & 11975 & 110 & 9.5 (7.9 to 11.5) & 64 & 9.3 (7.3 to 11.9) & 46 & $9.9 \quad$ (7.4 to 13.2) \\
\hline $40-49$ & 4068 & 74 & 19.2 (15.3 to 24.2 ) & 44 & 19.3 (14.3 to 26.0$)$ & 30 & 19.1 (13.3 to 27.4) \\
\hline $50-99$ & 3887 & 117 & $30.0(25.0$ to 36.1$)$ & 69 & 30.2 (23.8 to 38.4 ) & 48 & 29.6 (22.2 to 39.5) \\
\hline$\geq 100$ & 589 & 42 & 59.0 (43.4 to 80.1) & 21 & 46.8 (30.4 to 72.1$)$ & 21 & 78.5 (51.0 to 120.9) \\
\hline
\end{tabular}

AST $=$ aspartate aminotransferase, $A L T=$ alanine aminotransferase.

${ }^{*}$ Adjusted for age, body mass index, smoking status, alcohol consumption, plasma glucose, serum total cholesterol, blood pressure, and family history of liver disease. 
Table 5 Relative risk of mortality from liver diseases in women by serum aminotransferase concentration at baseline (expressed as floating absolute risks)

\begin{tabular}{|c|c|c|c|}
\hline & \multirow{2}{*}{$\begin{array}{l}\text { Total No of } \\
\text { participants }\end{array}$} & \multicolumn{2}{|c|}{ Liver diseases } \\
\hline & & No of deaths & $\mathrm{RR}^{*}(95 \% \mathrm{Cl})$ \\
\hline \multicolumn{4}{|l|}{ AST (IU/I): } \\
\hline$<20$ & 25362 & 3 & 1.0 (0.3 to 3.2$)$ \\
\hline $20-29$ & 19463 & 9 & 3.3 (1.7 to 6.4$)$ \\
\hline $30-39$ & 2114 & 6 & 18.2 (8.1 to 40.4$)$ \\
\hline $40-49$ & 336 & 3 & 46.1 (14.9 to 147.4$)$ \\
\hline$\geq 50$ & 247 & 2 & 46.2 (11.0 to 180.4$)$ \\
\hline \multicolumn{4}{|l|}{ ALT (IU/I): } \\
\hline$<20$ & 35187 & 6 & 1.0 (0.4 to 2.3) \\
\hline $20-29$ & 10201 & 8 & 3.8 (1.9 to 7.7$)$ \\
\hline $30-39$ & 1380 & 2 & 6.6 (1.5 to 25.6 ) \\
\hline $40-49$ & 365 & 5 & 68.3 (27.4 to 162.0 ) \\
\hline$\geq 50$ & 389 & 2 & 21.5 (5.3 to 85.6$)$ \\
\hline
\end{tabular}

AST=aspartate aminotransferase, ALT=alanine aminotransferase

${ }^{*}$ Adjusted for age, body mass index, smoking status, alcohol consumption, plasma glucose, serum total cholesterol, blood pressure, and family history of liver disease.

morality from liver diseases by reviewing data on hospital admissions.

Potential limitations of this study include the brief information on pre-existing diseases, lack of other laboratory tests for liver diseases, and non-standardised aminotransferase assays. Firstly, as the objective medical history of the study population was not available, we used the information provided by participants. We excluded people who indicated that they had any previously known diseases. We also assessed the confounding effects of unknown pre-existing disease by comparing the results by different follow up periods. However, the difference in the follow up period did not affect the association (table 6). Secondly, we did not study viral marker or perform liver function tests other than aminotransferase assays in the baseline examination. Individuals with the family history of liver disease are at high risk of the chronic hepatitis B virus infection because the infection is common in Korea, 5-10\% in men and $1-5 \%$ in women, and transmitted horizontally in high frequency. ${ }^{17}{ }^{23}$ We assessed the effects of the family history of liver disease using a stratified analysis. The results showed that family history of liver diseases did not alter the outcome of the study (fig 2). Thirdly, 419 hospitals over the country conducted the health examination and the serum aminotransferase assay was not standardised. All hospitals, however, followed the internal and external quality control procedures as stipulated by the Korean Society of Quality Control in Clinical Pathology. The
Table 6 Relation between serum aminotransferase concentration and mortality from liver disease in men by follow up period. Figures are relative risks* $(95 \%$ confidence intervals)

\begin{tabular}{|c|c|c|}
\hline & Year 1993-6 & Year 1997-2000 \\
\hline \multicolumn{3}{|c|}{ Serum aspartate aminotransferase level (IU/I): } \\
\hline$<20$ & 1.0 (0.6 to 1.7$)$ & $1.0 \quad$ (0.6 to 1.8) \\
\hline $20-29$ & $1.8 \quad(1.3$ to 2.4$)$ & $3.3 \quad$ (2.6 to 4.3$)$ \\
\hline $30-39$ & 6.4 (4.8 to 8.7$)$ & $10.0 \quad$ (7.6 to 13.0$)$ \\
\hline $40-49$ & 17.2 (11.8 to 25.2$)$ & $36.3 \quad$ (26.9 to 49.1$)$ \\
\hline $50-99$ & 46.8 (36.5 to 59.9$)$ & $89.4 \quad$ (71.9 to 111.2$)$ \\
\hline$\geq 100$ & 61.6 (38.9 to 97.6$)$ & $178.8(115.5$ to 254.9$)$ \\
\hline \multicolumn{3}{|c|}{ Serum alanine aminotransferase level (IU/I): } \\
\hline$<20$ & $1.0 \quad(0.6$ to 1.6$)$ & $1.0(0.7$ to 1.5$)$ \\
\hline $20-29$ & 3.1 (2.4 to 4.2$)$ & $2.7 \quad(2.1$ to 3.4$)$ \\
\hline $30-39$ & 12.5 (9.7 to 16.3$)$ & $7.6 \quad$ (5.8 to 9.9$)$ \\
\hline $40-49$ & $21.4(15.2$ to 30.2$)$ & 17.8 (13.1 to 24.2$)$ \\
\hline $50-99$ & 27.5 (20.4 to 36.9$)$ & 31.6 (25.0 to 40.0$)$ \\
\hline$\geq 100$ & 30.0 (16.0 to 55.9$)$ & 82.8 (58.4 to 117.5$)$ \\
\hline
\end{tabular}

Adjusted for age, body mass index, smoking status, alcohol consumption, plasma glucose, serum total cholesterol, blood pressure, and family history of liver disease.

variation index score was acceptable: 107 for aspartate aminotransferase and 109 for alanine aminotransferase. ${ }^{24}$ The misclassification bias, if any, is likely to be non-differential reduction of the relative risk. Hence, the results are unlikely to be distorted by measurement error.

\section{Conclusion}

Our findings indicate that serum aminotransferase concentration is associated with mortality from liver disease, even within the current normal range. To prevent early death related to liver diseases, individuals with slightly increased aminotransferase concentration should be observed closely and tested further for the presence of diseases. The adjustment of the normal limit of serum aminotransferase may be necessary, especially in populations in which liver diseases are common.

We thank the National Health Insurance Corporation (former the Korea Medical Insurance Corporation) for providing the data.

Contributors: HCK contributed to study concept and design, analysis and interpretation of the data, and preparation of the manuscript. CMN and $\mathrm{SHJ}$ contributed to study design, data analysis and interpretation, and editing the manuscript. $\mathrm{KHH}$ and DKO contributed to data analysis and interpretation and editing of the manuscript. IS contributed to study concept and design, analysis and interpretation of data, preparation of the manuscript, and supervision of the study and is guarantor.
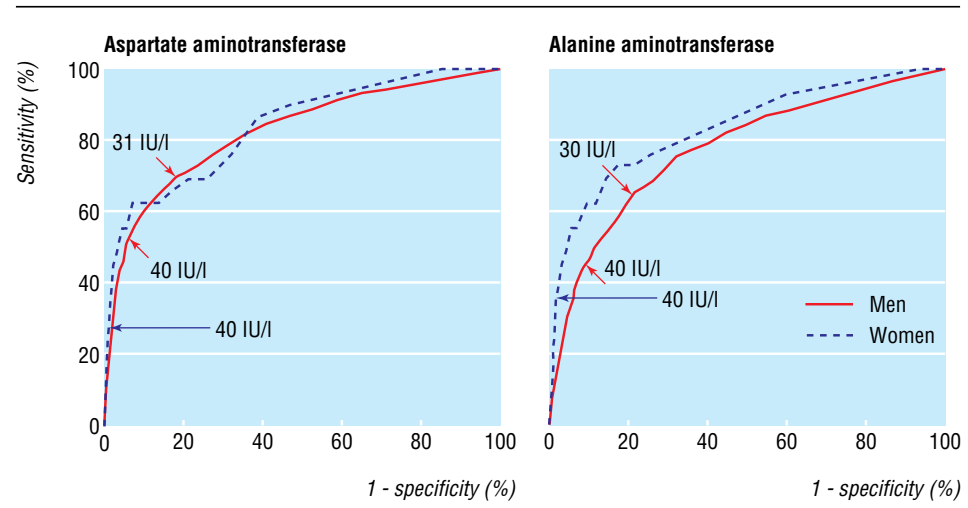

Fig 1 Receiver operating characteristic (ROC) curves of serum aminotransferase concentration for identification of people at risk of death from liver diseases 

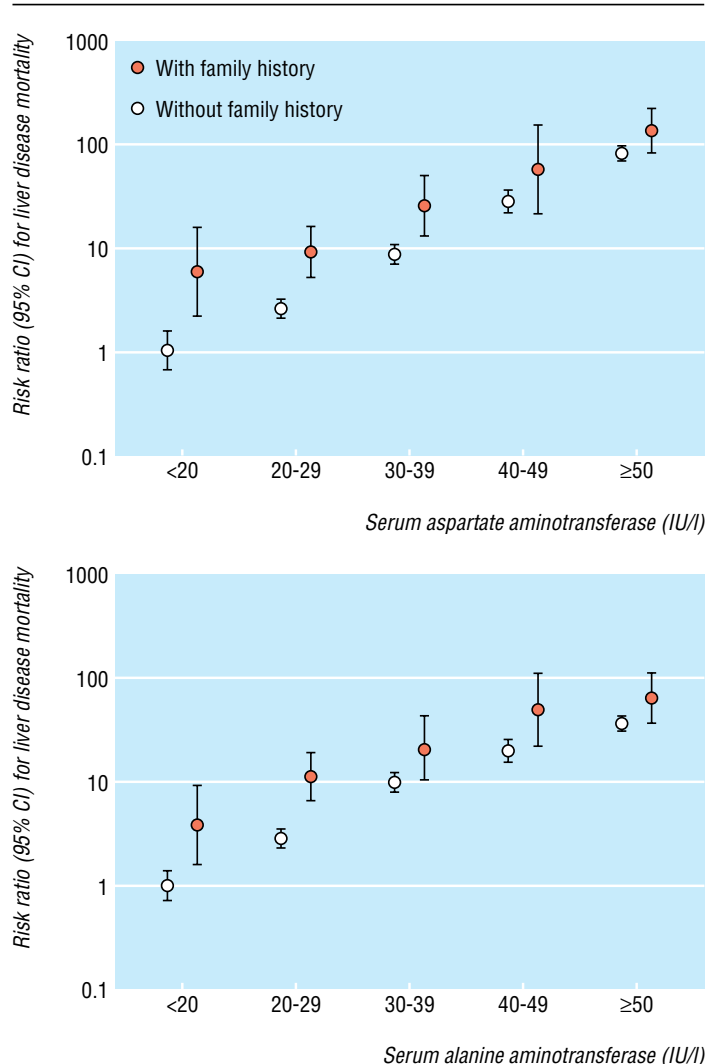

Fig 2 Association between serum aminotransferase concentration and mortality from liver disease in men by presence of family history of liver disease (expressed as floating absolute risks)

Funding: Supported, in part, by a grant from the 21C Frontier Functional Human Genome Project of the Ministry of Science and Technology of Korea.

Competing interest: None declared.

Ethical approval: Institutional review board of Severance Hospital at Yonsei University.

\section{What is already known on this topic}

The serum aminotransferase test with upper normal limit of $40 \mathrm{IU} / \mathrm{l}$ can identify liver damage

Little is known about the association between the normal range of the serum aminotransferase concentration and mortality

\section{What this study adds}

Serum aminotransferase concentration, even under $40 \mathrm{IU} / \mathrm{l}$, is positively associated with mortality from liver disease

The sensitivity of the serum aminotransferase test with the current normal range is low in identifying individuals at risk of death from liver disease

Lowering the normal range of the serum aminotransferase concentration is advisable in populations in which liver diseases are common
1 Seist G, Schiele F, Galteau M, Panek E, Steinmertz J, Fagnani F, et al. Aspartate aminotransferase and alanine aminotransferase activities in plasma: statistical distributions, individual variations, and reference values. Clin Chem 1975;21:1077-87.

2 Sherman KE. Alanine aminotransferase in clinical practice. A review. Arch Intern Med 1991;151:260-5.

3 Pratt DA, Kaplan MM. Evaluation of abnormal liver-enzyme results in asymptomatic patients. N Engl J Med 2000;342:1266-71.

4 Prati D, Taioli E, Zanella A, Torre ED, Butelli S, Del Vecchio E, et al. Updated definitions of healthy ranges for serum alanine aminotransferase levels. Ann Intern Med 2002;137:1-9

5 Chobanian AV, Bakris GL, Black HR, Cudhman WC, Green LA, Izzo JL, et al. The seventh report of the joint national committee on prevention, detection, evaluation, and treatment of high blood pressure. JAMA 2003;289:2560-72.

6 Easton DF, Peto J, Babiker AG. Floating absolute risk: an alternative to relative risk in survival and case-control analysis avoiding an arbitrary reference group. Stat Med 1991:10:1025-35.

7 Hultcrantz R, Claumann H, Lindberg G, Nilsson L. Liver investigation in 149 asymptomatic patients with moderately elevated activities of serum aminotransferase. Scand J Gastroenterol 1986;21:109-13.

8 Jensen D, Dickerson DD, Lindermann MA, Kessler H. Serum alanine aminotransferase levels and prevalence of hepatitis A, B, and Delta in outpatients. Arch Intern Med 1987:147:1734-7.

9 Mathiesen UL, Franzen LE, Fryden A, Foberg U, Bodemar G. The clinical significance of slightly to moderately increased liver transaminase values in asymptomatic patients. Scand J Gastroenterol 1999;34:85-91.

10 Pradat P, Alberti A, Poynard T, Esteban JI, Weiland O, Marcellin P, et al. Predictive value of ALT levels for histologic findings in chronic hepatitis C: a European collaborative study. Hepatology 2002;36:973-7.

11 Gholson CF, Morgan K, Catinis G, Favrot D, Taylor B, Gonzalez E, et al. Chronic hepatitis $\mathrm{C}$ with normal aminotransferase levels: a clinical histologic study. Am J Gastroenterol 1997;92:1788-92.

12 Jamal MM, Soni A, Quinn PG, Wheller DE, Arora S, Johnston DE. Clinical features of hepatitis C-infected patients with persistently normal alanine transaminase levels in the Southwestern United States. Hepatology 1999;30:1307-11.

13 Perisico M, Persico E, Suozzo R, Conte S, De Seta M, Coppola L, et al. Natural history of hepatitis $\mathrm{C}$ virus carriers with persistently normal aminotransferase levels. Gastroenterol 2000;118:760-4.

14 Salvaggio A, Periti M, Miano L, Tavanelli M, Marzorati D. Body mass index and liver enzyme activity in serum. Clin Chem 1991;37:720-3.

15 Piton A, Poynard T, Imbert-Bismut F, Khalil L, Delattre J, Pelissier E, et al. Factors associated with serum alanine transaminase activity in healthy subjects. Hepatology 1998;27:1213-9.

16 Guzzanoli G, Grugni G, Minocci A, Moro D, Morabito F. Liver steatosis in juvenile obesity. Int J Obes 2000;24:772-6.

17 Ahn YO. Recent change in HBV carrier rate among Koreans. JAMA-Korea 1999;SeptOct:382-3.

18 National Statistical Office. Annual report on cause of death statistics 2001. Seoul: National Statistical Office, 2002.

19 Kaplan MM. Alanine aminotransferase levels: what's normal? Ann Intern Med 2002;137:49-51.

20 Tsai JF, Chuang LY, Jeng JE, Ho MS, Lin ZY, Hsieh MY, et al. Serum alanine aminotransferase level in relation to hepatitis $\mathrm{B}$ and $\mathrm{C}$ virus infections among blood donors. Liver 1997;17:24-9.

21 Hung KY, Lee KC, Yen CJ, Wu KD, Tsai TJ, Chen WY. Revised cutoff values of serum aminotransferase in detecting viral hepatitis among CAPD patients: experience from Taiwan, an endemic area for hepatitis B. Nephrol Dial Transplant experience from
1997:12:180-3.

22 Espinosa M, Martin-Malo A, Alvarez de Lara MA, Soriano S, Aljama P. High ALT levels predict viremia in anti-HCV-positive $\mathrm{HD}$ patients if a modified normal range of ALT is applied. Clin Nephrol 2000;54:151-6.

23 Chun BY, Lee MK, Rho YK. The prevalence of hepatitis B surface antigen among Korean by literature review. Korean J Epidemiol 1992;14:54-62.

$24 \mathrm{Kim}$ YK. Kwon OH, Kim KD. Annual report on external quality assessments in clinical chemistry in Korea (1992).J Clin Pathol Qual Cont 1993;15:1-13.

(Accepted 28 January 2004)

doi $10.1136 /$ bmj. .38050 .593634 .63

Department of Preventive Medicine and Public Health, Yonsei University College of Medicine, 134 Shinchon-Dong, Seodaemun-Gu, Seoul 120-752, Republic of Korea

Hyeon Chang Kim instructor

Chung Mo Nam associate professor

Il Suh professor

Graduate School of Health Science and Management, Yonsei University, Seoul Sun Ha Jee assistant professor

Department of Internal Medicine, Yonsei University College of Medicine, Seoul Kwang Hyub Han professor

Bureau of Health Promotion, Ministry of Health and Welfare, Republic of Korea Dae Kyu Oh director

Correspondence to: I Suh isuh@yumc.yonsei.ac.kr 